\title{
The Design of PTA Wastewater Reuse Project
}

\section{Feng Yuchao}

Environmental Design Department, China Kunlun Contracting \& Engineering Corporation, Beijing, China

\section{Email address:}

fengyuchao@cnpc.com.cn

\section{To cite this article:}

Feng Yuchao. Reuse Project of PTA Wastewater. Science Discovery. Vol. 6, No. 3, 2018, pp. 171-174. doi: 10.11648/j.sd.20180603.15

Received: March 13, 2018; Accepted: May 3, 2018; Published: June 23, 2018

\begin{abstract}
Processing system design size of $1000 \mathrm{~m}^{3} / \mathrm{h}$ reuse of PTA project, and its waste water is characterized by large amount of discharge, complexity of pollutants and high concentration of manganeseions. Using ultrafiltration and reverse osmosis treatment method, supplement finished water recirculating cooling water, with its considerable economic benefit and good environmental benefits.
\end{abstract}

Keywords: PTA Wastewater, Reusetreatment, Ultrafiltration, Reverse Osmosis

\section{某PTA废水中水回用工程设计工艺研究}

\section{冯宇超}

环境工程设计部，中国昆仑工程有限公司，北京，中国

\section{邮箱}

fengyuchao@cnpc.com.cn

摘要：某PTA项目中水回用处理系统设计规模为 $1000 \mathrm{~m}^{3} / \mathrm{h}$, 本工程采用以“预处理十超滤+反渗透”为主的工艺路线, 对 PTA生化后废水中的有机物、盐分、锰、钴等重金属污染物的去除率较高并且运行稳定，产水回用于循环冷却水或除 盐水系统，具有可观的经济效益和良好的环保效益。

关键词: PTA废水, 中水回用, 超滤, 反渗透

\section{1. 引言}

精对苯二甲酸（PTA）是一种重要的石油化工产品, 是生产聚酯的主要原料, 应用广泛 ${ }^{[1]}$, 其装置是在醋酸溶 剂 (HAc) 中, 以对二甲苯 (PX) 为原料, 醋酸钴和醋酸 锰为催化剂, 溴化氢为促进剂, 分别经过氧化单元和精制 单元制得高纯度的PTA产品[2-3]。

在PTA生产过程中，用水量及废水排放量较大，水资源 短缺与水污染问题成为其进一步发展的制约因素 [4-5]。近年 来, PTA生产企业为节约用水、降低排污量, 纷纷积极尝试、 考察各种水回用技术, 选择切实可行的水回收方案。

PTA生产排放废水回用技术的应用，实现了水资源的回 收再利用, 节约生产成本, 将促进PTA工业的可持续发展。
由于膜分离技术对有机物及盐分的截留率较高并且稳定[6-7], 因此考虑膜技术作为主要的处理技术，实现废水的回用。

本文以某石化企业PTA生产废水生化处理后出水为 对象, 采用以“预处理+超滤十反渗透”为主的工艺, 研究其 处理工艺的工艺参数, 为PTA废水中水回用提供技术依据, 具有一定的推广价值。

\section{2. 水质分析}

\section{1. 水质特性}

PTA废水中除了含盐量较高, 还有一定量的悬浮物和 有机物。PTA工业生产流程, 中间添加了一定的催化剂, 
催化剂中含有一定量锰和钴离子, 会对聚酰胺材质的透膜 造成不可弥补的伤害, 所以需要特别注意和单独去除 [8-10]。

\section{2. 进出水水质}

表1 进出水水质表。

\begin{tabular}{|c|c|c|c|c|c|}
\hline 指标 & 单位 & 进水 & 预处理产水 & 超滤产水 & 反渗透产水 \\
\hline $\mathrm{pH}$ & & $6.0-9.0$ & $6.0-9.0$ & $7.5-8.5$ & $6.0-7.5$ \\
\hline SS & $\mathrm{mg} / \mathrm{L}$ & $\leq 50$ & & $\leq 5$ & \\
\hline COD & $\mathrm{mg} / \mathrm{L}$ & $\leq 73$ & & & $\leq 5$ \\
\hline T-H & $\mathrm{mg} / \mathrm{L}\left(\mathrm{CaCO}_{3}\right)$ & $\leq 310$ & & & $\leq 140$ \\
\hline M-Alk & $\mathrm{mg} / \mathrm{L}\left(\mathrm{CaCO}_{3}\right)$ & $\leq 2600$ & & & $\leq 180$ \\
\hline Turb. & NTU & & & $\leq 1$ & $\leq 2$ \\
\hline Cond. & $\mu \mathrm{m} / \mathrm{cm}$ & $\leq 5430$ & & & $\leq 350$ \\
\hline SDI & & & & $\leq 5$ & \\
\hline $\mathrm{Co}^{2+}$ & $\mathrm{mg} / \mathrm{L}$ & $\leq 3.0$ & $\leq 1.0$ & & $\leq 0.1$ \\
\hline $\mathrm{Mn}^{2+}$ & $\mathrm{mg} / \mathrm{L}$ & $\leq 3.0$ & $\leq 1.0$ & & $\leq 0.1$ \\
\hline $\mathrm{NH}_{3}-\mathrm{N}$ & $\mathrm{mg} / \mathrm{L}$ & $\leq 2.42$ & & & \\
\hline T-P & $\mathrm{mg} / \mathrm{L}$ & $\leq 12.8$ & & & \\
\hline $\mathrm{SO}_{4}{ }^{2-}$ & $\mathrm{mg} / \mathrm{L}$ & $\leq 40.6$ & & $\leq 60$ & \\
\hline $\mathrm{Cl}^{-}$ & $\mathrm{mg} / \mathrm{L}$ & $\leq 50$ & & $\leq 50$ & \\
\hline
\end{tabular}

\section{3. 工艺流程及设计参数}

现有PTA污水生化处理系统, 排放水质达到一级排放 标准。由于废水 (生化系统排水) 含盐量较高且含一定量 $\mathrm{COD}$, 采用传统生化处理技术难以达到回用标, 而膜分离 技术对污染物的截留率较高并且稳定; 本工程采用以“预 处理+超滤十反渗透”为主的工艺路线, 将现有的生化排水 深度处理后, 回用于循环冷却水或除盐水系统。

本装置设计处理量为 $1000 \mathrm{~m}^{3} / \mathrm{h}$, 工艺流程及处理量示 意如下:

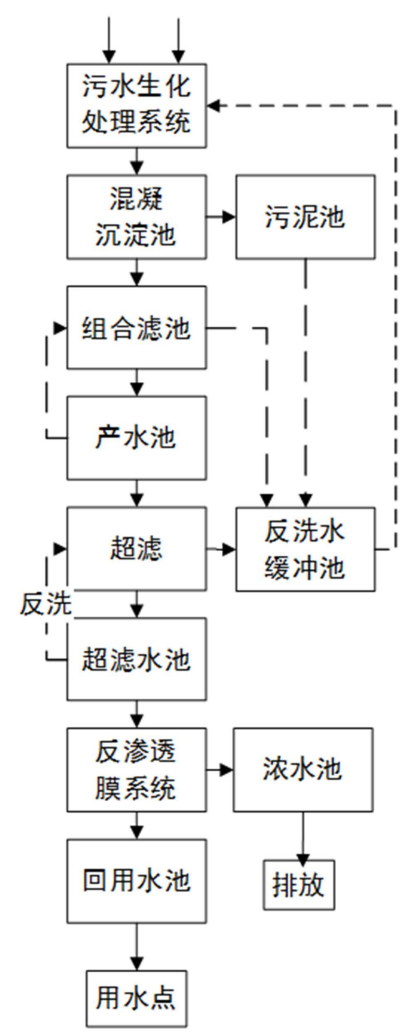

图1 工艺流程图。

\section{1. 预处理系统}

包括混凝沉淀池、V 型滤池。

\subsection{1. 混凝沉淀池}

混凝是水处理中经常采用的方法, 它的处理对象是原 水中利用自然沉淀难以去除的细小悬浮物以及胶体颗粒, 这些颗粒很难用自然沉淀法从水中分离出去。混凝的过程 是通过向原水中投加混凝剂, 使细小悬浮颗粒和胶体微粒 聚集成较粗大的颗粒而沉淀, 从而与原水分离, 达到降低 原水的浊度和色度的效果。

本系统混凝沉淀池共设2座。来水中含有部分颗粒物, 加入适量絮凝剂PAC, 使污染物形成絮体至后段沉淀区进 行固液分离; 加入 $\mathrm{NaClO}$, 用于抑制原水中的微生物; 加 入 $\mathrm{NaOH}$ ，调节进水 $\mathrm{pH}$ ，增强絮凝效果。

混合了药剂的原水折流进入后续折流反应池和混凝 反应池。加入化学试剂的原水在混凝池作用下充分混合后 流体向下流入沉淀池布水孔, 通过蜂窝状斜管填料作用, 达到泥水分离。固液分离后的上清液通过出水槽溢流到下 一道工艺。

沉淀池定期通过底部的排泥管道及排泥阀, 在重力的 作用下将沉积下来的污泥、杂物等自动排出沉淀池, 汇总 进入污泥池, 污泥池内液位上升达到一定高度后, 通过排 泥泵打到反洗水缓冲池。

\subsubsection{V型滤池}

由于生化处理出水, 根据运行的情况SS会有一定的波 动, $\mathrm{V}$ 型滤池利用一定直径的砂石、按一定的方式叠放, 形成过滤层, 水中的悬浮物在通过滤层的时候被截留而去 除, 克服生化处理的不规则性, 保证出水水质稳定可靠。 V型滤池中装填卵石、石英砂等组合滤料, 还可去除部分 $\mathrm{COD}$ 和锰、钴等重金属, 保护和改善后续膜系统的运行。 $\mathrm{V}$ 型滤池共设4座, 可单座或同时4座运行。V型滤池产水 进入滤池产水池储存。 


\subsection{3. 预处理系统构筑物及设备配置}

表2 预处理系统构筑物一览表。

\begin{tabular}{lll}
\hline 名称 & 数量 & 设计参数 \\
\hline 混凝池 & 2 & $12800 \times 2500 \times 6400 \mathrm{~mm}$ \\
沉淀池 & 2 & $29700 \times 16400 \times 6400 \mathrm{~mm}$ \\
V型滤池 & 4 & $15200 \times 7600 \times 4000 \mathrm{~mm}$ \\
污泥池 & 1 & $26625 \times 600 \times 1300 \mathrm{~mm}$ \\
滤池产水池 & 1 & $19400 \times 15400 \times 3500 \mathrm{~mm}$ \\
反洗水缓冲池 & 1 & $15400 \times 10000 \times 3500 \mathrm{~mm}$ \\
\hline
\end{tabular}

表3 预处理系统设备一览表。

\begin{tabular}{lll}
\hline 名称 & 数量 & 设计参数 \\
\hline 混凝池摚拌机 & 2 & 桨叶 304 \\
V型滤池反洗风机 & 2 & $55 \mathrm{~m}^{3} / \mathrm{min} / 49 \mathrm{kPa} / 75 \mathrm{~kW}$ \\
V型滤池反洗水洜 & 3 & $480 \mathrm{~m}^{3} / \mathrm{h} / 15 \mathrm{~m} / 37 \mathrm{~kW}$ \\
V型滤池电动闸门 & 4 & $450 \times 450 \mathrm{~mm}$ 铸铁 \\
污泥池排泥原 & 2 & $50 \mathrm{~m}^{3} / \mathrm{h} / 25 \mathrm{~m} / 7.5 \mathrm{~kW}$ \\
反洗水外排㬌 & 2 & $205 \mathrm{~m}^{3} / \mathrm{h} / 40 \mathrm{~m} / 45 \mathrm{~kW}$ \\
\hline
\end{tabular}

\section{2. 超滤系统}

系统设计超滤装置6套。设计总处理量 $1055 \mathrm{~m}^{3} / \mathrm{h}$, 产 水 $\mathrm{SDI} \leq 3.0$, 产水浊度 $\leq 0.1$, 回收率大于 $88 \%$ 。设计产水膜 通量35LMH。本工程选用外压式中空纤维超滤膜 (DOW, SPF2880）, 具有较高的截污量, 较大的过滤面积, 使清 洗更简便、彻底。

预处理系统的滤后水经超滤进水泵打入自清洗过滤 器过滤, 再进入超滤膜组件中过滤产水; 超滤产水进入超 滤产水池, 用于反渗透系统脱盐处理和超滤自身反洗、分 散洗。

超滤系统工作时, 一般可以按照其所处的工作状态, 分为: 运行、反洗、分散化学清洗和化学清洗。大约 20 40min进行一次反洗, 大约 6 12h进行一次分散化学清 洗。在反洗进水中, 投加次氯酸钠进行杀菌, 以控制微生 物对膜的污染。

表4 超滤系统构筑物一览表。

\begin{tabular}{lll}
\hline 名称 & 数量 & 设计参数 \\
\hline 超滤产水池 & 1 & $16500 \times 15000 \times 4000 \mathrm{~mm}$ \\
\hline
\end{tabular}

表5 超滤系统设备一览表。

\begin{tabular}{lll}
\hline 名称 & 数量 & 设计参数 \\
\hline 超滤进水葲 & 4 & $437 \mathrm{~m}^{3} / \mathrm{h} / 25 \mathrm{~m} / 55 \mathrm{~kW}$ \\
自清洗过滤器 & 3 & $350 \mathrm{~m}^{3} / \mathrm{h} / 200 \mu \mathrm{m}$ \\
超滤反洗泉 & 3 & $260 \mathrm{~m}^{3} / \mathrm{h} / 20 \mathrm{~m} / 30 \mathrm{~kW}$ \\
压缩空气储罐 & 1 & $5 \mathrm{~m} / 38 \mathrm{~kg}$ \\
超滤反洗保安过滤器 & 2 & $250 \mathrm{~m}^{3} / \mathrm{h} / 100 \mu \mathrm{m}$ \\
\hline
\end{tabular}

当反洗次数到达设定值, 或膜污染较重、产水流量较 低时, 自动进入分散清洗过程, 选定的 $\mathrm{NaClO}$ (或 $\mathrm{NaOH}$ 、 $\mathrm{HCl}$ 、柠檬酸) 向膜组件内进药, 浸泡时间到达后, 再自 动进行一次反洗过程。

当膜组件污染较严重（K值下降 $40 \%$ ），常规反洗和 分散清洗数次后, 膜通量恢复仍不能满足生产要求, 需进 行在线化学清洗, 以强化清洗和恢复膜通量。

\section{3. 反渗透系统}

系统设计反渗透装置 5 套。设计总处理量 $928 \mathrm{~m}^{3} / \mathrm{h}, 70 \%$ 回收率, 产水量 $650 \mathrm{~m}^{3} / \mathrm{h}$, 浓水量 $278 \mathrm{~m}^{3} / \mathrm{h}$, 设计膜通量 $14.5 \mathrm{LMH}$, 脱盐率 $\geq 95 \%$ 。基于原水 $\mathrm{COD}$ 较高, 且有可能 遭受污染, 本工程反渗透选用宽流道抗污染反渗透膜 （DOW-BW30XFR-400/34i），该膜具有表面光滑抗有机 物污染等优点, 采用两段的膜组件配置方式, 按 $28: 14$ 设 置膜组件的排列方式。

超滤产水加入一定浓度的 $\mathrm{HCl}$, 通过反渗透进水洜打 入反渗透系统, 同时自动加入还原剂和阻垢剂, 反渗透进 水先经保安过滤器截留大颗粒物质, 再经高压㫤增压到所 需入膜压力, 进入一段膜组件过滤, 浓水经中间增压泵增 压后进入二段膜组件继续过滤, 二段浓水直接排放到浓水 池。一段、二段产水汇总进入反渗透产水池, 再通过回用 水输送洜输送至循环水系统或者除盐水系统。

当膜污染较重, 停止产水, 系统自动冲洗, 置换膜组 件内的浓水, 再停机切换到清洗模式, 进行化学清洗, 根 据膜污染现象, 判断污染物种类, 在用相应的清洗剂进行 清洗。清洗完毕后, 测试水通量, 通量恢复后转入产水。

表6 反渗透系统构筑物一览表。

\begin{tabular}{lll}
\hline 名称 & 数量 & 设计参数 \\
\hline 反渗透产水池 & 1 & $14000 \times 15000 \times 4000 \mathrm{~mm}$ \\
反渗透浓水池 & 1 & $7500 \times 15000 \times 4000 \mathrm{~mm}$ \\
\hline
\end{tabular}

表7 反渗透系统设备一览表。

\begin{tabular}{|c|c|c|}
\hline 名称 & 数量 & 设计参数 \\
\hline 反渗透进水洜 & 6 & $190 \mathrm{~m}^{3} / \mathrm{h} / 40 \mathrm{~m} / 45 \mathrm{~kW}$ \\
\hline 反渗透高压洜 & 5 & $220 \mathrm{~m}^{3} / \mathrm{h} / 120 \mathrm{~m} / 132 \mathrm{~kW}$ \\
\hline 反渗透增压洜 & 5 & $120 \mathrm{~m}^{3} / \mathrm{h} / 25 \mathrm{~m} / 15 \mathrm{~kW}$ \\
\hline 反渗透进水保安过滤器 & 5 & $200 \mathrm{~m}^{3} / \mathrm{h} / 5 \mu \mathrm{m}$ \\
\hline 回用水输送洜 & 3 & $330 \mathrm{~m}^{3} / \mathrm{h} / 30 \mathrm{~m} / 55 \mathrm{~kW}$ \\
\hline 浓水输送洜 & 3 & $140 \mathrm{~m}^{3} / \mathrm{h} / 35 \mathrm{~m} / 30 \mathrm{~kW}$ \\
\hline
\end{tabular}

\section{4. 运行实况分析}

该项目于2014年开始投入工业应用，到目前为止，装 置运行基本稳定, 出水水质很好地满足脱盐水水质要求。

\section{5. 效益分析}

此中水回用工程为脱盐水补充水回用到主装置, 水回收 系统年运行时间按 $8400 \mathrm{~h}$ 计, 则产水量为 $5460000 \mathrm{~m}^{3} /$ 年。从 系统运行的统计上看, 则水回收系统产水成本为 1.6673 元 $/ \mathrm{m} 3$ 。而电厂脱盐水的制备费用为 5 元 $/ \mathrm{m}^{3}$, 即每产生 $1 \mathrm{~m}^{3}$ 脱盐 水可节约费用为 3.33 元 $/ \mathrm{m}^{3}$, 年节约 18196542 元, 经济效益可 观。同时, 减少了污水排放量, 实现较大的环保效益。

表8 工程运行成本一览表。

\begin{tabular}{lll}
\hline 名称 & 年费用 $/$ 元 & 吨水费用 $/\left(\right.$ 元 $\left./ \mathbf{m}^{3}\right)$ \\
\hline 电耗 & 2335075 & 0.4277 \\
药耗 & 2781625 & 0.5095 \\
超滤、反渗透、滤芯更换费用 & 3987002 & 0.7302 \\
合计 & 9103702 & 1.6673 \\
\hline
\end{tabular}




\section{6. 结语}

双膜法在国内已应用成熟，随着国家对水资源控制趋 于严格, 中水回用趋势更为明显。采用“预处理+超滤十反 渗透”工艺, 能有效去除污水中的有机物、盐分、锰、钴 等重金属, 产水可回用至循环冷却水补水或除盐水站。 PTA污水的再生利用, 减少污水排放量, 提高水资源利用 率, 是企业实现可持续发展的必由之路。

\section{参考文献}

[1] 崔国刚。我国精对苯二甲酸生产现状及市场分子 $[\mathrm{J}]$ 。合成 纤维非工业, 2016,39（3）:48-51。

[2] 田华,王颖.PTA废水预处理研究[J].黑龙江水利专业学报, 2000，27(3): 51-53。

[3] 陈健美,兰瑞勃, 孔庆昱,等.精制对苯二甲酸装置废水处理的 节能控制[J]. 化工技术经济，1999，17(3)：34-35。
[4] 崔晓明.精对苯二甲酸生产废水处理技术进展[J]. 聚酯工业, 2014, 27(1): 1-5。

[5] 马佳威,雷玲,钱枝茂,等. 精制对苯二甲酸生产废水处理及 回用技术探讨 [J]. 能源化工，2015，36(6)：37-41。

[6] 黄瑞婷. “双膜法”在PTA母液废水回用系统的应用[J].节能 环保, 2017, 2(13): 1-2。

[7] 王锦龙, 林丽华, 蒋林熠. 双膜法在PTA中水回用系统的 应用[C]. 2009年邮寄颜料行业年会及海峡两岸有机颜料发 展趋势论坛资料集: 145-148。

[8] 赵会艳.PTA污水回用过程中PVDF膜污染剖析[J].水处理技 术, 2015，41(9)：75-77。

［9］徐成燕. 江苏洪港石化PTA中水回用工程双膜法的方案设 计及探讨 $[J]$. 广东化工，2014，41(19)：152-153。

[10］徐竟成, 魏巧玲.PTA废水锰砂生物过滤/反渗透深度处理工 艺研究[J].净水技术, 2009，28(4)：162-165。 